"This is an Author's Original Manuscript of an article submitted for consideration in the [JOURNAL TITLE] [copyright Taylor \& Francis]; Regional Studies is available online at http://www.tandfonline.com/DOI: 10.1080/00343404.2013.859666

\title{
SEASONALITY OF OVERSEAS TOURISM DEMAND IN SCOTLAND: A REGIONAL ANALYSIS
}

\author{
John Coshall, Richard Charlesworth \& Stephen J. Page
}

Preprint Version: July 2013

\section{INTRODUCTION}

Seasonality structures and shapes human activity in time and space, particularly the consumption of the built and natural environment for tourism and leisure (PALANG, SOOVALI and PRINTSMAN, 2010) and it is one of the most protracted problems facing managers in the tourism sector. Seasonality translates into a mismatch of supply and demand at a destination level, expressed as a "temporal imbalance in the phenomena of tourism" (BUTLER, 1994, 332). Therefore, the principal research challenge for many destinations is to find tools or interventions that may obviate the scale and scope of seasonality, to more fully maximise the destination assets and resources. Yet few critical reviews exist which assess the extent to which seasonality has been impacted amidst major investments in the marketing of a destination overseas and the effect this has had at a regional scale. Scotland is one such destination which received major investment in a public sector destination marketing organisation (DMO), where its budget rose from around $£ 24$ million in 2000 to $£ 58$ million in 2012. Scotland is a destination that has recognised that it has an underuse of 
resources due to seasonal influences upon tourism demand ${ }^{\mathrm{ii}}$. In 2006, VisitScotland reported that one half of the approximately 40 million bednights available across all accommodation sectors went unused (VISITSCOTLAND, 2007b). Running in parallel to this is the repositioning of the destination after 2002 in response to criticisms of a structural decline in international visitation from the mid-1990s (see KERR, 2003) and a lack of industry leadership by the DMO. A redesigned DMO (VisitScotland) reoriented its budget towards international and domestic marketing based upon a brand proposition to refresh a tired and outdated international destination image to broaden its market appeal, especially internationally. The focus on the international market as a key sector was predicated on the higher economic value attributed to each international visitor and the value added to the visitor economy compared to domestic visitor spending. Therefore, with approximately $£ 200$ million per annum spent by public sector agencies on tourism infrastructure, promotion and development, it is pertinent to examine one key research question on seasonality and Scottish tourism: How has seasonality manifest itself at a regional scale in Scotland 1996-2009? Yet Baum and Lundtorp (2001: 1) argue that "One of the problems in really understanding seasonality in tourism is the lack of in-depth and longitudinal research". Therefore, the underlying rationale for selecting such a timeframe (aside from data availability), was the need to select a period which also encapsulated the structural changes that occurred in international visitation $^{\text {iii }}$. However prior to examining the methodology, concepts and results, it is pertinent to briefly some of the key literature gaps in knowledge to highlight an absence of more micro-scale studies of seasonality within individual countries.

\section{THE TOURISM-SEASONALITY LITERATURE}

A number of influential reviews of the state of the art of seasonality research exist (e.g. KOENIG and BISCHOFF, 2005; BAUM and LUNDTORP, 2001; BUTLER and MAO, 1997; JANG, 2004). The distinct strands of research reviewed by KOENIG and BISCHOFF 
(2005) provide an overview of issues such as the nomenclature and causes of seasonality, their impacts, policy implications and the types of public and private sector interventions which may assist in addressing seasonality temporally and spatially. A range of studies have highlighted differences in occupancy rates between the seasons (JEFFREY et al., 2002; AMELUNG and VINER, 2006; HOTI et al., 2007), the impact of on employment (KRAKOVER, 2000; NESHEIM, 2003; GETZ and NILSSON, 2004), the role of climatic factors in determining seasonal demand (BARTOLOME et al., 2009), the under- and overutilisation of resources during off-peak and peak periods (HINCH and JACKSON, 2000; KENNEDY and DEEGAN, 2001), the possible implications of climate change on seasonality (AMELUNG et al., 2007) and problems of seasonality in peripheral areas (COMMONS and PAGE, 2001; KASTENHOLZ and DE ALMEIDA, 2008). Individual measures to address seasonality involve hosting events in low seasons in order to spread demand and to help fill existing capacity (SPENCER and HOLECEK, 2007), whilst reducing peak demand and redistributing demand at peak times as well as additional capacity at peak times, whilst businesses deploy marketing resources and price promotions to fill capacity during periods of surplus supply. Yet the existing literature, with a number of exceptions (e.g. CHARLESEDWARDS, 2004; AMELUNG et al, 2007; BENDER et al, 2005), have not focused on the spatiality of seasonality and the implications within destinations. Yet without such a focus, it is impossible to formulate and assess the impact of policy interventions directed at seasonal issues especially at the regional level (KOENIG and BISCHOFF, 2004; KARAMUSTAFA and ULAMA, 2010).

In theoretical terms, the paper moves the conventional analysis of seasonality from a focus on causes (e.g. accessibility, climatic factors, market mix, available products and tourist preferences, public sector intervention and the hosting of events) to examine the effects of seasonality in a place-specific context. In other words, the paper addresses the locality 
implications of seasonality questioning the validity of using established terms such as 'core' (lowland urban Scotland and towns) and 'periphery' (Highlands and Islands of Scotland and rural areas) which have been widely cited as explanations of tourism seasonality (VISITSCOTLAND, 2007a). Using a disaggregated model of tourism seasonality data, it is possible to begin to assess the analysis of seasonality within a spatial framework (i.e. using the region as a unit of analysis), building upon previous studies that highlighted country differences in seasonality using domestic tourism data (KOENIG and BISCHOFF, 2003). This paper moves our understanding of seasonality to a more geographical focus combining economic and spatial analysis, expanding upon aggregated perspectives of seasonality data (e.g. KOENIG-LEWIS and BISCHOFF, 2010). The research utilises a large governmentgenerated tourism dataset - the UK International Passenger Survey (IPS) - and appropriate methodologies (i.e. the Gini Coefficient and Amplitude Ratios and Principal Components Analysis) to assess spatial and temporal patterns of seasonality in overseas tourism in Scotland at a regional level. The study uses quarterly data disaggregated from 1996 to 2009 inclusive $^{\text {iv }}$ By trip purpose to capture the variations which exist temporally and spatially between vacation trips, visiting friends and relatives (VFR) and business travel as highlighted by KOENIG and BISCHOFF (2003).

\section{METHODOLOGY AND CONCEPTS}

A wide range of methods have been used to measure seasonal variations in tourism (e.g. CUCCIA and RIZZO, 2011) with the most comprehensive review by KOENIG and BISCHOFF (2003) which outlined the most commonly used methods of analysis (i.e. the Coefficient of Variation; Coeffiecient of Variability; the Gini Coefficient; Seasonal factors from Decomposition; Peak Season Share; Amplitude Ratios; the Similarity Index) which provide a comparative methodological perspective that need not be reiterated here given the constraints of space ${ }^{\mathrm{v}}$. BAR-ON (1975) argued that tourism-related time series are well 
represented by multiplicative time series models in which the seasonal component $S_{t}$ and random (or irregular) component $R_{t}$ are expressed as percentages of the trend $T_{t}$ at period $t$. In such models, the seasonal element varies proportionately with the level of the trend, a characteristic typical of tourism data series (BAR-ON, 1999; WALL and YAN, 2003). The multiplicative model represents an observed time series, $\mathrm{Y}_{\mathrm{t}}$, as:

$$
Y_{t}=T_{t} \times S_{t} \times R_{t}
$$

A classical decomposition of the data, often using moving averages, is used to establish the trend. It then becomes possible to isolate the seasonality $\mathrm{S}_{\mathrm{t}}$ (referred to here as the Seasonal Index) from the trend and other factors and $S_{t}$ can be used to measure the magnitude of seasonal changes within a year. It should be noted that $S_{t}$ can be employed in different ways. In some studies, seasonal variations are averaged over the long-term and are expressed in percentage terms, whereas others focus on deviations within each year.

A variety of scalar measures has been developed to measure seasonality, although as KOENIG-LEWIS and BISCHOFF (2005) illustrate, some studies use different names for the same measure and the same (or similar) names for different measures. BAR-ON's (1975) seminal study used the Seasonality Range and Seasonality Ratio. Both are based on the seasonal indices (as percentages) derived from a multiplicative (monthly) model. These indices are weighted to take into account different lengths of months and are termed 'intrinsic seasonal factors'. For each year, the principal peak $\mathrm{S}_{\mathrm{P}}$ and trough $\mathrm{S}_{\mathrm{T}}$ are used to define the Seasonality Range $\left(S_{\mathrm{P}}-\mathrm{S}_{\mathrm{T}}\right)$ and Seasonality Ratio $\left(\mathrm{S}_{\mathrm{P}} / \mathrm{S}_{\mathrm{T}}\right)$. The magnitude of the seasonal swing is therefore captured, but no account is taken of the pattern of seasonality. YACOUMIS (1980) employed a differently defined Seasonality Ratio, based on the ratio of the peak seasonal index for the year to the average index (which is 100) across the year and also computed the Coefficient of Seasonal Variation which is the standard deviation of the 
seasonal indices for the year. However, it has been argued that it is difficult to ascribe an appropriate interpretation to this coefficient (LUNDTORP, 2001). KOENIG and BISCHOFF (2003) prefer to use the inverse of YACOUMIS' (1980) Seasonality Ratio, but based on the original units of measurement rather than percentages, terming this the Seasonality Indicator with an upper bound of 1 corresponding to no seasonal differences in the data. KOENIGLEWIS and BISCHOFF (2005) note that the Seasonality Ratio could be defined as the highest seasonal value divided by the lowest and this simple definition is employed in this study.

The Gini Coefficient (GC) (GINI, 1912) measures inequalities in data and has long been used by a variety of disciplines, particularly in economics to compare economic performance (PORTER, 2003), income distribution (JOHNSTON et al., 1996) or poverty across regions or countries. It captures seasonal movements in tourism (KOENIG and BISCHOFF, 2003), being derived from the Lorenz curve and is defined as the area between the curve and the diagonal (line of equality), divided by the area below the diagonal (see WANHILL, 1980). The GC takes a value of zero if there is no seasonal variation (seasonal inequality) and a maximum value of $1-1 / \mathrm{n}$ if there is maximum inequality (i.e. all of the seasonal variation occurs in one time period), where $\mathrm{n}$ is the number of points within each seasonal cycle (DELTAS, 2003). With quarterly data, $\mathrm{GC}_{\mathrm{MAX}}=0.75$. NADAL et al. (2004) advocated the use of the GC to detect seasonal patterns in tourism data and supported arguments in its favour on the grounds of robustness with skewed data (WANHILL, 1980) and its overall capacity to highlight seasonal concentration and dispersion by being more sensitive to variations outside the peak season (see LUNDTORP, 2001 for more detail on the GC and Amplitude Ratio and methodological issues associated with their use; NADAL et al., 2004). Consequently, the GC was used in the present study, with its numerical value being based on 
the areas of the trapeziums below the Lorenz curve, which give rise to the formula for the GC in year $\mathrm{j}$ (WEN and TISDELL, 2001):

$$
\mathrm{GC}_{\mathrm{j}}=1+\frac{1}{\mathrm{n}}-\left[\frac{2}{\mathrm{n}^{2} \overline{\mathrm{Y}}}\right]\left(\mathrm{Y}_{1}+2 \mathrm{Y}_{2}+3 \mathrm{Y}_{3}+\ldots .+\mathrm{nY} \mathrm{Y}_{\mathrm{n}}\right)
$$

where $\mathrm{n}$ is defined as above, $\mathrm{Y}_{\mathrm{i}}$ are the numbers of overseas visitor nights spent at a particular location, decreasing in magnitude so that $\mathrm{Y}_{1}>\mathrm{Y}_{2}>\mathrm{Y}_{3}>\ldots>\mathrm{Y}_{\mathrm{n}}$, and $\overline{\mathrm{Y}}$ is the mean number of visitor nights for the year at hand.

However, due to the above ordering required for the computation of the GC, changes in the seasonal pattern within a year will not be picked up, mainly because its limitation is the independence from any time period. Consequently, this study also uses the Amplitude Ratio (AR) (KUZNETS, 1932) building on its use by KOENIG and BISCHOFF (2003) and CHARLES-EDWARDS (2004). The AR is particularly effective at highlighting the consistency of a seasonal pattern over time and captures the concentration of seasonal movements (DRAKATOS, 1987). It thereby acts as a complement to the GC. The first step in computing the $\mathrm{AR}$ is to use a centred four-point moving average to determine the trend in overseas visitor nights from Q1 1996 to Q4 2009. The percentage deviation $d_{i j}$ ( $i=1$ to 4) of each of the quarterly points from the trend is computed for every year $\mathrm{j}$. Seasonal Factors $\mathrm{s}_{\mathrm{i}}(\mathrm{i}$ $=1$ to 4 ) were derived over the entire study period, expressed as deviations of the Seasonal Index from 100 , so $s_{i}=S_{i}-100$. The $A R$ in year $j$ is then defined as:

$$
\mathrm{AR}_{\mathrm{j}}=\frac{\sum_{\mathrm{i}} \mathrm{d}_{\mathrm{ij}} \mathrm{s}_{\mathrm{i}}}{\sum_{\mathrm{i}} \mathrm{s}_{\mathrm{i}}^{2}}
$$

If $\mathrm{AR}_{\mathrm{j}}=1$, the seasonal amplitude in year $\mathrm{j}$ matches that of the average seasonal index. Therefore, if the ARs are consistently close to unity year by year, it suggests a high level of 
stability across that time period (CHARLES-EDWARDS, 2004). If $\mathrm{AR}_{\mathrm{j}}<1$ (> 1), the amplitude in year $\mathrm{j}$ is smaller (larger) than the average.

\section{FINDINGS}

The total numbers of quarterly overnight stays made by international tourists to Scotland for the purposes of business, vacation or VFR tourism are presented in Fig. 1 for Q1 1997 to Q4 2009 inclusive $^{\mathrm{vi}}$. The trend in international visitors saw a drop in visitor numbers between 1996 to 2003 (including the impact of events such as Foot and Mouth and 9/11) with a degree of growth after 2003 through to 2009 with visitor numbers peaking at 2.79 million in 2007 dropping to 2.59 million in 2009 . In 2009, overseas tourists stayed nearly 22 million nights in Scotland, with $42 \%$ of bednights occupied by vacation tourists, $34 \%$ visiting friends and relatives and $9 \%$ business tourists. The remaining $15 \%$ involved visitors for other purposes, (e.g. educational trips). These 2009 percentages are in fact close to the average figures for the whole study period. The United States, Republic of Ireland, Germany, Spain and France have consistently been major source markets for Scottish tourism since 1996, while strong growth has been seen in more recent years from Poland, Italy, Australia and Italy.

Fig.1 illustrates a clear pattern of seasonality with peaks and troughs and the key findings can be summarised thus:

- Between 1997 and 2009, an annual average of 73\% of all vacation, VFR and business tourism occurred in the second and third quarters of the year; quarter 3 was dominated by vacation tourists.

- Equivalent yearly averages are $11 \%$ for quarter 1 and $16 \%$ for quarter 4 . 
- There is more variability in the quarter 3 peaks than in the quarter 1 troughs.

- Aggregate tourism demand has seasonal effects with much the same annual timing but appear variable in impact (e.g. before 2002, there is minimal variation in the numbers of quarter 1 overnight stays).

- Fluctuating peak numbers 1996-2009 result in Seasonality Ratios (defined as per KOENIG-LEWIS and BISCHOFF, 2005) of quarter 3 (peak) to quarter 1 (trough) overnight stays that vary between 5.0 and 6.4 (albeit using data collected on a monthly basis).

- Relatively low peaks in quarter 3 of both 2008 and 2009 coincide with the onset of the global financial crisis, with respective numbers of visitor nights being $20 \%$ and $11 \%$ below the equivalent 2007 figure.

- Marginally increasing quarter 1 numbers contributed to drops in the equivalent Seasonality Ratios of 3.2 (2008) and 2.7 (2009).

- The intensity of seasonal fluctuations in overseas visitor nights spent in Scotland markedly decreases in 2008 and 2009, but at the expense of reduced visitor nights in the summer.

- A decline in the volume of overseas visitors to the UK in the third quarter of 2001 occurred due to the foot and mouth outbreak earlier in the year (BLAKE et al., 2003; COSHALL, 2003; BUTLER and AIREY, 2005; EUGENIO-MARTIN et al., 2005). Numbers of overseas nights spent in Scotland fell by nearly $14 \%$ in relation to Q3 2000, thereby reducing the Seasonal Ratio to 4.7 in 2001.

- For 2002 and 2003 the Seasonal Ratio remained relatively low as the events of September $11^{\text {th }}$ impacted on levels of international tourism, especially in relation to transatlantic vacation tourism in quarter 3 (COSHALL, 2005). 
Fig. 2 presents the percentages of overseas vacation nights per quarter in each of the thirteen regions into which the IPS subdivides Scotland (see Fig. 4 for a regional map). The key findings are as follows:

- Universal dominance of the April to September months over the October to March period is clear. This seasonal disparity is most marked for the Argyll, Highland and Island regions, with only $10 \%, 11 \%$ and $12 \%$ respectively of their vacation nights occurring in quarters 1 and $4^{\text {vii }}$.

- Scotland has a mean GC value of 0.436 and a standard deviation of 0.085 for overseas visitor nights between 1996 and 2009.

Regional GC values were computed for the numbers of nights spent by overseas vacation tourists each year. Average GC values per region for 1996 to 2009 show that:

- The greatest levels of seasonal inequality are found in the relatively more rural regions - Argyll (mean GC $=.522$ ) to the north-west of the central lowlands, through the bordering Highlands (mean GC $=.528$ ) and up to the Islands (mean GC $=.540$ ). These three regions involve the highest percentages of around $70 \%$ of overnight vacation stays concentrated into quarter 3.

- Other largely rural regions have equivalent figures of between 55\% and $62 \%$.

- In the case of the Islands region especially, dominance of a short visitor season and distance from major sources of demand, over and above the advantages offered by that area's scenic, wildlife and historical resources remain the major reasons why seasonality is the foremost constraint to tourism development, just as it was 20 years ago (SLEE, 1998), with seasonal air and ferry services constraining access outside of the peak season. 
- The three coterminous regions in central lowland Scotland of Glasgow-Clydeside $($ mean GC $=.393)$, Strathclyde-Ayr $($ mean GC $=.403)$ and Lothian $($ mean GC $=.417)$ (which is dominated by the city of Edinburgh), are typically characterised by the least seasonal intensity in overseas holiday bednights during the calendar year. These regions and their $\mathrm{GC}$ values indicate that seasonality is less pronounced in the numbers of overnight stays to these more accessible, relatively urbanised regions - a characteristic that has continued from the mid-1990s.

- Destinations within range of large urban centres experience less marked seasonality because of their ability to satisfy more varied demand for overnight stays and their relative accessibility with two main gateways (Edinburgh and Glasgow) and a smaller gateway at Prestwick.

- All regions have annual peak numbers of vacation visitor nights in quarter 3 which are largely climatic and institutional-led (i.e. related to the main holiday season). The minimum number of visitors usually occurs in quarter 1 , but on just over one fifth of occasions it occurs in quarter 4.

- The annual amplitude between peaks and troughs varies in size for some regions more so than for others. ARs were computed to quantify the stability or persistence of the regions' seasonal patterns over time. Average values of AR were close to unity for all 13 regions. This suggests that in the long-run, a region's average annual seasonal amplitude tends to correspond with that of the region's average seasonal index (i.e. increases and decreases in seasonal variation cancel out over time). However, this fails to consider important variation in the seasonal concentration of overnight stays spatially and in the short-run. 
The standard deviation of the ARs reflects variation in the intensity of a region's seasonal fluctuations over time and these statistics are presented in Fig. 3. The key findings are as follows:

- The Strathclyde-Loch Lomond and Borders regions exhibit the highest levels of inconsistency in the persistence of seasonal effects.

- The highest AR values for Strathclyde-Loch Lomond of 1.754 and 1.695 occurred in 1999 and 2005 respectively, indicating that the amplitudes at those times were well above the average.

- The relatively high variation in levels of seasonal inequality in the two regions is apparent. The 1999 peak for Strathclyde-Loch Lomond was due to a relatively low number of vacation nights in that year's minimum period of quarter 4 compared with quarter 3, suggesting an under-utilisation of resources in the winter period. The 2005 peak was due to the highest numbers of peak period visitor nights relative to a minimum quarter 4 figure, signifying greater demand than usual on resources that summer.

- The lowest levels of seasonal inequality were found in 2003 and 2008, both being due to relatively low numbers of summer visitor nights compared with those in the quarter 1 periods of lowest demand, this time being indicative of an under-utilisation of resources in those summers. The region is dominated by the Loch Lomond and Trossachs National Park and this relatively high level of variation in seasonal intensity for bednights makes the planning, provision and forecasting of recreational demand on the region a difficult task.

- Seasonality effects in the Borders region are similarly uneven over time, with periods of high seasonal inequality in 1999, 2004 and 2007 and periods of low inequality in 2000, 2005 and 2008. 
- The more urbanised Lothian, Glasgow-Clydeside and Central regions tend to show relatively low levels of temporal variation in the strength of seasonal effects in Fig. 3, but there again, this is also noticeable for the largely rural Argyll region and the more peripheral Highland, Island and Grampian regions.

These findings suggest that inter-regional similarities in the variation of seasonal effects exist between distant regions sometimes with dissimilar economic characteristics. Furthermore, the annual values of the ARs for overseas vacation nights spent in Scotland show little variation over time (falling between 0.834 and 1.141). Such aggregation disguises important disparities in the intensity of seasonal variation at the regional and temporal level. Patterns of

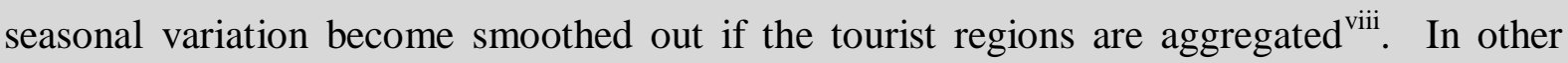
words, there is a spatial element to the study of seasonality, but that this does not consistently involve nearest neighbours or regions with similar geographical characteristics. In order to represent the spatial dimension of seasonality in vacation nights graphically, the regional GC values were subjected to Principal Components Analysis with a varimax rotation ${ }^{\mathrm{ix}}$. Table 1 indicates that over $80 \%$ of the variation in the GCs is accounted for by five regional components.

\section{Principal Components Analysis of Regional Gini Coefficients}

The component loadings of Table 2 permit mapping of these regional groupings as presented in Fig. 4. A first component of Fig. 4 indicates high inter-correlations between the GCs of the Fife and Lothian regions on the North Sea eastern coast of Scotland, through GlasgowClydeside and on to the Strathclyde regions in the west. These contiguous regions incorporate the Edinburgh-Leith and Glasgow-Clydeside conurbations and are the most urbanised part of Scotland, containing over $70 \%$ of its population ${ }^{\mathrm{x}}$. The average GCs in this area are close to or more often lower than the Scottish average and are indicative of the 
relatively low levels of seasonal concentration in overnight stays alluded to earlier (i.e. an urbanisation of overseas vacation demand at off-peak periods of the year). The second component mapped in Fig. 4 relates to the high levels of seasonal intensity suggested earlier for Argyll and the Highlands, although the Islands region is not included in this grouping as might have been expected from Fig. 2. This is because although the Islands region shares a similar degree of seasonality and accessibility with Argyll and the Highlands, it shows greater variability in the seasonal effect over time as shown in Fig. 3. At the beginning of the study period in 1996, Highlands and Islands Enterprise aimed to attract large numbers of ski tourists, hillwalkers and mountaineers would be attracted to the Highlands region. Given that quarters 1 and 2 are the peak periods for these activities, it was anticipated that the tourism season would thereby be lengthened (HIGHLANDS AND ISLANDS ENTERPRISE, 1996). However, numbers of overseas tourists attracted by these activities have been insufficient to reduce the strong element of seasonality in vacation tourism over the ensuing years in spite of recent investments in infrastructure (e.g. the regeneration of the Aviemore area). Accessibility is the principal explanation (apart from a cluster of activity concentrated at a growth pole at Fort William in the north-west and the regional administrative centre of the Highlands - Inverness in the north-east), component 2 is categorised as being made up of 'remote rural areas' ${ }^{\text {xi }}$ and 'very remote rural areas, ${ }^{\text {xii }}$.

The third component involves similar patterns of seasonality in the Central and Islands regions. This supports the finding of BENDER et al. (2005) that the categorisation of tourist regions in terms of their seasonal effects can reveal similarities that are not restricted by proximity. Although the strength of the seasonal effect is greater in the Islands than it is in the Central region, Fig. 4 indicates that both regions have similar and relatively low levels of variation in strength of the seasonal effect on a year by year basis. 
A fourth regional grouping involves the neighbouring Borders and Dumfries-Galloway regions in the south of Scotland. Fig. 4 illustrates that both regions have comparable, below average levels of seasonal concentration that are nevertheless subject to relatively high levels of variation over time. In 2005, the second highest numbers of overseas nights spent in Scotland occurred during the study period; but both regions had low GC values because of low summer peaks in vacation nights relative to their continually low quarter 1 figures. Conversely, 1999 was at the time a typical year for overseas tourist nights, yet these two regions generated the highest summer peaks relative to the quarter 1 numbers of bednights in that year. The Borders and Dumfries-Galloway regions span the Southern Uplands of Scotland and are composed of roughly equal measures of 'accessible' and 'remote' areas, plus a few 'very remote' zones. Consequently, variation in seasonal intensity must in part be related to climatic conditions. It is probably also related to the fact that the ratio of domestic to overseas tourists to the regions is high at 10:1. The fifth component involves the TaysidePerthshire region with its northerly neighbour, the Grampians. Both regions have seasonal concentrations that are above the Scottish norm and they have similar patterns of variation in the seasonal effect over time. They both have consistently low quarter 1 visitor nights that have remained fairly constant since 1996. Large GCs for both regions in 2006 and 2007 are due to high quarter 3 peaks relative to the winter months. On the other hand, these regions exhibit the low GC values for the years 2001 to 2003. These latter values are typical for Scotland as a whole and are due to low numbers of visitor nights in quarter 3 relative to quarter 1. Overall, these findings offer only partial support for a core-periphery spatial pattern in the character of seasonal intensity that has been found elsewhere (JEFFREY and BARDEN, 1999). The peripheral north-west, north-east and southern regions of Scotland do exhibit different patterns of seasonal concentration relative to the core central regions, but this does not imply that the peripheral regions are themselves homogeneous in this respect. 
Indeed, for vacation markets, rural Scotland is certainly not a uniform entity and these findings highlight the importance of further analysis of the regional aspects of seasonality at the more microspatial scale where gateways to regions (e.g. National Parks) and transport hubs determine the spatial patterns of visitation combined with climatic factors. 
VFR is a largely neglected area of study within tourism research, although $64 \%$ of all overseas VFR nights in Scotland were spatially concentrated in the urbanised regions (Glasgow-Clydeside, 30\%; Lothian, 25\% and Grampian 9\%). The city of Edinburgh accounted for $92 \%$ of VFR nights in Lothian and Aberdeen $72 \%$ of the Grampians reflecting the urbanised nature of VFR visitation. The average GC value for VFR nights in the Scottish regions as a whole was 0.329 (which is less than the equivalent figure for overseas vacation nights) indicating that the seasonal effect is typically less intense for the country. This has some parallels with domestic VFR tourism which is also less prone to seasonal effects than are vacation markets (SEATON and PALMER, 1997). Fig. 5 plots the numbers of VFR nights spent in all of the Scottish regions. It is often assumed that VFR is the more resilient form of tourism during austere economic times (KING, 1996). The key findings are as follows:

- Both the numbers of overseas VFR and vacation nights in Scotland responded to the global financial crisis of mid-2008 with a drop in the peak quarter 3 arrivals and a consequent drop in the seasonal effect.

- The impact is far less significant for VFR nights, both in terms of numbers and Seasonality Ratios. In 2006 and 2007, these ratios were 2.8 and 3.1 respectively for VFR nights, falling to 2.3 (2008) and 2.2 (2009). In 2006 and 2007, these ratios had respective values of 10.1 and 13.7 for vacation nights, dropping to 6.1 and 7.9 in 2008 and 2009, due to a marked reduction in summer demand for tourism.

Average annual GC values for VFR nights are plotted in Fig. 6. Comparison of Fig. 6 with the equivalent results for vacation nights highlights that urban tourism is less seasonal than tourism per se and the key findings are as follows: 
- The GC values in Fig. 6 are less than the equivalent figures for overseas vacation nights for all of the 13 regions: hence the lower seasonal inequality observed at the national scale is universal at the spatially disaggregated level.

- Reduced seasonal intensity suggests that VFR tourism has the potential to act as a 'seasonal compensation' (ASIEDU, 2008; BOYNE, 2001; BACKER, 2007) to the general tourism flow patterns over time by providing visitors in low- and shoulderseason periods throughout all of the Scottish regions.

- Christmas and the New Year Hogmanay festivities have some input to a more even distribution of regional overseas VFR nights during the years studied, but the effect is much less marked than that observed for UK domestic VFR tourism, which can peak at times of traditionally generally low tourism volumes, especially December (SEATON and PALMER, 1997) $)^{\mathrm{xiii}}$.

- Averages (to the nearest thousand) of 338000 and 354000 VFR nights occur in quarters 1 and 4 for the Glasgow-Clydeside region. The equivalent figures are 245000 and 265000 for the Lothian region.

- As well as attracting the largest numbers of off-peak VFR nights, Glasgow-Clydeside (mean GC $=0.184$ in Fig. 6) and Lothian (mean GC $=0.230$ ) exhibit by far the lowest levels of seasonal concentration. Both regions have similar percentages of VFR nights occurring in quarters 1,2 and $4-20 \%, 21 \%$ and $21 \%$ respectively for Glasgow-Clydeside and 18\%, 20\% and 21\% for Lothian. The numbers of overnight stays involved in these two dominating regions means VFR tourism acts to 'compensate' for the general seasonal imbalance of tourism in Scotland.

- At the other extreme, the Island (mean GC $=0.425)$ and Highland (mean GC $=0.354$ ) regions in the north and the Dumfries and Galloway (mean $\mathrm{GC}=0.406$ ) and Borders 
(mean GC $=0.400$ ) regions in the south have the highest seasonal focus of VFR nights concentrated in quarters 2 and 3 where climate and access constrain demand.

- The numbers of VFR nights spent outside of these quarters 2 and 3 other than in Glasgow-Clydeside and Lothian are relatively modest and contribute little to towards smoothing out the overall seasonal concentration of tourist nights during the year.

Standard deviations of the regional ARs for VFR nights are plotted in Fig. 7 and the key findings are as follows:

- The least variation in seasonal effects is found for the Strathclyde-Lomond and Borders regions.

- The seasonal polarisation of VFR nights in these two regions into the months between April and September is relatively persistent over time.

- These two regions have the most volatile seasonal effects in respect of vacation nights as was illustrated in Fig. 3.

- Trip purpose is an integral feature of the seasonality phenomenon, yet consideration of aggregate data even at the regional level would mask the above findings.

- The Dumfries-Galloway region has not only high levels of annual seasonal concentration for VFR nights; the region also exhibits the greatest variations in seasonal amplitude. Fife has close to the national average levels of seasonal intensity for VFR nights (Fig. 6), but like Dumfries-Galloway it too shows relatively high variations in seasonal amplitude over the years.

The annual GC values for VFR nights spent in Dumfries and Galloway and the average annual GC values for Scotland exhibit marked variations in the levels of seasonal concentration of VFR nights over time in these two regions is clear. Variation from the late 1990s to the middle 2000s follows a broadly similar pattern. However, from 2006 onwards, 
any common trend vanishes and the onset of the financial crisis is associated with a reduction in seasonal concentration in Fife, while there is a polarisation in Dumfries-Galloway. It would be expected that the crisis would exhibit no systematic regional effect on seasonal inequality for VFR nights. This is because there is strong evidence that VFR tourists' overall expenditures are lower than for other forms of tourism because of an absence of package trip costs and insignificant spending on accommodation (MORRISON et al., 2000; LEE et al., 2005). Consequently, there is less financial incentive for VFR tourists to take advantage of such as off-peak discounts and to vary their travel plans. The changes in GCs between 2008 and 2009 indicate that seasonal inequality for international VFR nights increased in three regions (Dumfries-Galloway, Grampians and the Highlands), decreased in five regions (Borders, Fife, Glasgow-Clydeside, Lothian and Tayside-Perthshire) and remained virtually unchanged for the remaining five IPS regions. Therefore, although the financial crisis reduced the numbers of overseas VFR nights spent in Scotland (Fig. 5), it had no consistent impact on seasonal concentration at the regional level.

Figs. 6 and 7 suggest that spatiality of seasonal effects is far less in evidence for VFR nights than it is for vacation nights, apart for the Glasgow-Clydeside and Lothian regions. Regional GC values for VFR nights were subjected to PCA with a varimax rotation to examine the spatial elements of seasonality. Although nearly $90 \%$ of the variation in the GCs was explained, this time by six regional components (details available on request), only one extracted component relating to the Glasgow-Clydeside and Lothian regions exhibited a geographical theme. It is interesting to note that although the PCA evidences that the seasonal concentrations in both regions are inter-related, unlike the situation for vacation nights, the Lothian region had consistently higher GC values than the Glasgow-Clydeside region from 1999 until the onset of the financial crisis. Fig. 8 shows that the latter region 
typically received larger percentages of VFR nights during quarters 1 and 2 but that this situation was quite markedly reversed in the third quarters resulting in the greater seasonal polarisation in the Lothians. Over a third of all tourism to Scotland involves VFR and possibly this higher seasonal intensity is a response to the fact that Edinburgh is an event-led destination that adopts a vigorous and professional approach to marketing the AugustSeptember Edinburgh festival and events like Hogmanay which attracted around 20,000 overseas visitors in 2009. The remaining components extracted from the PCA did not involve nearest neighbours or IPS regions with similar geographical characteristics. There is no evidence of a core-periphery spatial pattern for seasonal inequalities in VFR nights in the style of Fig 4.

\section{Regional seasonality in overnight stays: overseas business tourism}

Business tourism is predominantly a three city phenomenon in Scotland for international visitors reflected in business nights spent (i.e. 35\% in Edinburgh; 32\% in Glasgow and 9\% in Aberdeen). However, numbers are relatively low with just over 2.0 million business nights spent in 2009 which represent $16 \%$ of all overseas visitor nights spent in Scotland. This has remained fairly consistent since 1996 . Thus while business nights represent a relatively small fraction of the total, overseas business tourism appears resilient in being able to maintain its proportionate market share over time which is reflected in the strategic investment and marketing to attract major events and conferences. This has received substantial investment in business tourism infrastructure (i.e. high quality accommodation in large volumes, facilities for Meetings, Incentive Travel, Conferences and Exhibitions, MICE) developed to compete globally and nationally to host MICE business ${ }^{\text {xiv }}$. The key features of overseas business tourism are as follows: 
- At the aggregate level, the yearly peak period for business nights in Scotland was in the third quarter (aside from 2008 when the quarterly maximum of 569000 nights (32\% of the annual total) occurred between January and March and in 2009, when quarter 2 produced a maximum figure of 798000 nights (38\%)).

- Such temporal consistency in patterns of seasonality is not replicated at the city level.

- Between 1996 and 2009, quarter 3 was not the peak period for seven years (six quarter $2 \mathrm{~s}$ and one quarter 1 ) in the case of Aberdeen; for three years (two quarter $2 \mathrm{~s}$ and one quarter 1) for Edinburgh; and four years (three quarter $2 \mathrm{~s}$ and one quarter 1) for Glasgow. This highlights the significance of promoting business tourism to fill accommodation capacity outside of the peak vacation demand with conferences and conventions.

Average GC values for the three urban areas are presented in Table 3, confirming that overseas business and VFR nights suffer from less seasonal variation than do vacation nights (KULENDRAN and WONG, 2005). From a policy perspective, international business tourism has the potential to increase tourism numbers, spending and resource utilisation in the off-peak periods, but the benefits will tend to be spatially concentrated in the major urban locations ${ }^{\mathrm{xv}}$. The average GCs for business nights are reasonably consistent for the three cities, but this disguises the year on year patterns of seasonal concentration. The standard deviations of the ARs in Table 3 reveal that Glasgow has the most inconsistent levels of seasonality in business nights. Urban GC values over the study period are plotted in Fig. 9 and the key findings are as follows:

- A high degree of variation exists due to the seasonal inequality of business nights in Glasgow which are low in $2001(\mathrm{GC}=0.073)$ and at the start of the recession in 2008 $(\mathrm{GC}=0.031)$. 
- Low GC values are due to greatly reduced business nights in quarter 3, while numbers in the remaining quarters remained consistent with previous years.

- Glasgow's low quarter 3 numbers are short-lived and recover within a year of the above dates and seasonal imbalance returns. Relatively high GC values are found in $1997(\mathrm{GC}=0.337)$ and $2000(\mathrm{GC}=0.331)$ when quarter 3 numbers of business nights spent in the city were particularly high.

- Conversely, the ARs for Edinburgh are all above unity between 1997 and 2004 inclusive. Therefore, the seasonal amplitude for these years is consistently greater than the average seasonal index for 1996-2009; these years show greater levels of seasonal concentration in business nights than on average.

- The seasonal effects are greatest in $2000(\mathrm{AR}=1.556 ; \mathrm{GC}=0.351), 2001(\mathrm{AR}=$ $1.772 ; \mathrm{GC}=0.448)$ and $2002(\mathrm{AR}=1.381 ; \mathrm{GC}=0.330)$. This is predominantly due to relatively low quarter 1 and 4 numbers and a relatively high quarter 3 figure. From 2005 onwards, Edinburgh's AR values are always less than unity indicating that each year's seasonal amplitude is less than average and that numbers of business nights are being spread more evenly throughout the year. Year on year increases in business nights in the non-peak period is doubtless the culmination of a sustained marketing strategy to win business events, especially conferences for the city (MORE, 2005).

- Overall, the last row of Table 3 shows that of the three cities, Edinburgh possesses the least degree of variation in the strength of seasonal fluctuations in overseas business nights since 1996.

- Aberdeen lies between Glasgow and Edinburgh in terms of seasonal concentration and variability of seasonal inequality for business nights. An average of just over $60 \%$ of business nights are concentrated into quarters 2 and 3 during the study period. However, the years up to 2002 exhibited the greatest swings in seasonality. 
- Seasonal effects were weakest in $1997(\mathrm{GC}=0.100, \mathrm{AR}=0.024,53 \%$ of business nights in Q2 and Q3) and $2002(\mathrm{GC}=0.109, \mathrm{AR}=0.080,47 \%$ in $\mathrm{Q} 2$ and Q3). They were strongest in $1998(\mathrm{GC}=0.373, \mathrm{AR}=1.731,74 \%$ in $\mathrm{Q} 2$ and $\mathrm{Q} 3)$.

- Between 2004 and 2009, levels of seasonal inequality become consistent year on year with GC values ranging from 0.236 in 2005 to 0.287 in 2007 . In part, this is because the Aberdeen accommodation market benefits from continual, all the year round demand supported by the strong oil and natural gas industries which are still experiencing steady growth. This also goes someway to explaining why quarter 3 is not the peak period for Aberdeen's international business tourism for half of the study period.

\section{CONCLUSIONS}

This study illustrates that seasonality is a fundamental element of international visitation to Scotland, building on KOENIG and BISCHOFF (2003). This paper displays a regional complexity in the spatiality of seasonality: the mix of visitor markets in Scotland have a variety of distinct geographical patterns, with the vacation market the most variable and the business market displaying more stable behaviour in time and space. The findings challenge the simple notion that all tourism in Scotland conforms to a simple core-periphery model of tourism in both time and space. The computation of AR values in conjunction with GCs have highlighted changing dynamics in regional seasonality over time, with the lowest levels of seasonal concentration of international vacation tourism found in the more urbanised and accessible core regions of the Central Lowlands. Conversely, the rural, remote Argyll and Highlands regions reveal the highest levels of seasonal concentration, illustrating that accessibility is a key factor in these two peripheral areas. There are also other less well explained processes at work that the microspatial analysis would yield results for individual localities, namely the impact of geographical displacement from the staging of major events 
and public sector interventions to create a clustering of activity in time and especially in space (i.e. at key locations). Geographical displacement remains an under-developed theme in tourism research since it has negative connotations with interventions that are designed to grow rather than offset tourism activity and the ability to either deter or shift demand to other regions.

Despite the above contrasting extremes of central Scotland and the Highlands, seasonal concentration in seasonality displays little variation over time as the impacts of seasonality on vacation tourism have become entrenched. This means that inspite of various marketing, and policy initiatives, vacation tourism has not changed little in terms of seasonality: this challenges the validity and effectiveness of overseas marketing of vacation tourism to achieve regional rebalancing of tourism demand. This may be a reason why some destinations, such as Bournemouth are turning to the under-explored concept of VFR and resident encouragement of visits. In areas where recent international labour migration from Eastern Europe and further afield, may help to grow this type of initiative. However, there is limited research on how specific initiatives in Scotland since 1996 have shifted seasonality and the fortunes of regions reliant upon the overseas markets, even though marketing campaigns seek to address the sector-wide problem of seasonality.

This research suggests that generic marketing in the shoulder season may misunderstand seasonality where the tourism sector promotes strategies to develop tourism as the following statement suggests: 'we need to develop assets in response to specific market opportunities. For example, ...destination towns and cities - more widely promoting the diversity of things to do, contemporary and traditional, within our destination towns and cities in order to extend their visitor seasons' (SCOTTISH TOURISM ALLIANCE, 2012: 9). This paper challenges the basis of this gross simplification of the regional diversity of seasonality within Scotland. This research also has to be viewed against the changing fortunes of international visitor 
volumes as lower seasonality and lower visitor numbers, for example, are unlikely to assist the economic development of tourism in the manner policy-makers wish to pursue. This illustrates why a carefully considered review of seasonality would benefit tourism policymaking and current thinking.

More fundamentally this study demonstrates the inadequacy of spatial policy to focus on existing areas where business, VFR and some elements of vacation tourism perform well and the need to target areas where more concerted action is needed to spread the distribution of benefits from tourism envisaged post-devolution (i.e. after 1999). This research points to the need for a policy reassessment of the geography of Scottish tourism beyond the areas which Scottish Enterprise as a development agency currently favour as key destinations for future investment and development since this is unlikely to make any inroads into regional seasonality. Spatial seasonality is a consequence of visitor behaviour temporally and spatially and draft Tourism Development Plan for Scotland (VISITSCOTLAND, 2013) largely overlooks seasonality even this is a key element in the business model for any new developments to grow Scottish tourism and its regional tourism economies. The rural, southern Borders and Dumfries-Galloway regions reveal levels of seasonal intensity that are below the Scottish norm, yet these are among the most variable over time. The TaysidePerthshire region (dominated by Dundee and Perth) and the Grampian region (dominated by Aberdeen) have levels of seasonal concentration above the Scottish norm, but which are less variable over time. Clearly the issue of seasonality is more than a simple separation of urban and rural areas. Whilst VisitScotland has recognised that the tourism market is increasingly being segmented into very specialist niches related to climate, environment, location and topography, this study can only disaggregate data for vacation tourism at the regional level. The next stage would be to link analyses such as are presented in this paper with data 
available in surveys such as the Visitor Attraction Monitor and the analysis at a more microspatial level.

The importance of disaggregating regional data by trip purpose is illustrated when considering overseas VFR tourism because it is to a large extent an urban phenomenon and is consequently less seasonal than vacation tourism. This means it has great potential if it is harnessed to address gaps in capacity. The lower seasonal concentration of VFR tourism is, however, not uniform across the regions. The Highlands, Islands and Argyll plus the Borders and Dumfries-Galloway regions in the south exhibit a strong seasonal focus of VFR tourism in quarter 3, suggesting that accessibility and institutional effects (i.e. School Holidays) are the drivers of the seasonal effect. However, variations in the strength of seasonal effects over time are inconsistent in these peripheral regions. VFR tourism could form a useful element of seasonal compensation (SEATON, 1998) since a reasonable proportion occurs outside of the peak season quarter 3. But this was only realised in the dominant Glasgow-Clydeside and Lothian regions and was certainly not evident in the peripheral regions. Similarly for business tourism, Edinburgh, exhibits the least variation in seasonal effects with quarterly numbers of business nights becoming consistently more evenly spread throughout the year since 2005 , doubtless a consequence of vigorous marketing strategies to gain more off-peak business events from the individual conference venues and wider business tourism strategy of VisitScotland. There is also some evidence that levels of seasonal concentration of business tourists has remained at a consistent level.

For the tourism sector, this research begins to question the simplistic notions that seasonality is a Scotland-wide issue that has no time-space dimension or distinctive regional pattern 
beyond the conventional distinction of urban lowland and highland/island. This runs contrary to the thinking amongst policy-makers which is largely aspatial beyond these broad generalisations of core and periphery into the urbanised central lowlands and a number of other urban clusters of activity (e.g. Aberdeen and St Andrews). In an evidence-based public sector environment where tourism management is normally reduced to simple notions of cause and effect (i.e. intervene at point $\mathrm{x}$ to create outcome $\mathrm{y}$ or to address a perceived market failure), the issue of tourism seasonality remains a highly neglected dimension of decisionmaking as short-term initiatives. To ignore the behaviour of tourists in time and space in any analysis of interventions designed to address perceived market failure or to indirectly reduce seasonal effects is an omission on the part of policy-makers and planners: seasonality is an underpinning element of business and human behaviour (PALANG, SOOVALI, PRINTSMAN, 2010) where specific actions are needed to influence behaviour change in tourists to offset seasonal effects. As a result, future marketing and advertising campaigns need to be more targeted and timed to address the spatial opportunities for filling capacity whilst developing urban-rural breaks and activities that combine two centre trips that spread the seasonal markets and create new opportunities that are not constrained by climatic or institutional or accessibility factors.

(9001 words)

\section{REFERENCES}

AMELUNG B. and VINER D. (2006) Mediterranean tourism: exploring the future with the tourism climatic index, Journal of Sustainable Tourism, 14(4), 349-366.

AMELUNG B., NICHOLLS, S. and VINER D. (2007) Implications of global climatic change for tourism flows and seasonality, Journal of Travel Research, 45(3), 285-296. 
ASIEDU A. B. (2008) Participants' characteristics and economic benefits of visiting friends and relatives (VFR) tourism - an international survey of the literature with implications for Ghana, International Journal of Tourism Research, 10, 609-621.

BACKER E. (2007) VFR travel - an examination of the expenditures of VFR travellers and their hosts, Current Issues in Tourism, 10(4), 366-377.

BAR-ON R.R. (1975) Seasonality in Tourism - a Guide to the Analysis of Seasonality and Trends for Policy Making. Technical Series No. 2, The Economist Intelligence Unit Ltd., London.

BAR-ON R.R. (1999) The measurement of seasonality and its economic impacts, Tourism Economics, 5(4), 437-458.

BARTOLOME A., MCALEER M., RAMOS V. and REY-MAQUIEIRA J. (2009) Modelling air passenger arrivals in the Balearic and Canary Islands, Spain, Tourism Economics, 15, 481-500.

BENDER O., SCHUMACHER K. P. and STEIN D. (2005) Measuring seasonality in Central Europe's tourism - how and for what? 10th International Conference on Information and Communication Technologies (ICT) in Urban Planning and Spatial Development and Impacts of ICT on Physical Space, 303-309 (available at http://www.corp.at/ corp relaunch/papers txt suche/CORP2005 BENDER.pdf).

BLAKE A., SINCLAIR M.T. and SUGIYARTO, G. (2003) The Economy-Wide Effects of Foot and Mouth Disease in the UK Economy. Nottingham University Business School, Nottingham, UK.

BOYNE S. (2001) Hosts, friends and relatives in rural Scotland: VFR tourism market relationships explored, in ROBERTS L. and HALL D. (Eds) Rural Tourism and Recreation: Principles to Practice, pp. 41-43. CABI Publishing, Wallingford. 
BUTLER R. (1994) Seasonality in tourism: issues and problems, in SEATON A.V. (Ed) Tourism: the State of the Art, pp. 332-339. Wiley, Chichester, UK.

BUTLER R. and AIREY D. (2005) The foot-and-mouth outbreak of 2001: impacts on and implications for tourism in the United Kingdom, in ARAMBERRI J. and BUTLER R. (Eds) Tourism Development: Issues for a Vulnerable Industry, pp. 215-238. Channel View, Clevedon, UK.

BUTLER, R. and MAO, B. (1997) 'Seasonality in tourism: problems and measurement', in MURPHY P. (Ed.) Quality Management in Urban Tourism, pp. 9-24, Wiley, Chichester.

CHARLES-EDWARDS E. (2004) Preliminary Analysis of the Degree and Patterns of Seasonal Mobility within Australia. Discussion Paper 2003/04, Queensland Centre for Population Research, School of Geography, Planning and Architecture, University of Queensland, Brisbane, Australia.

COMMONS J. and PAGE S. J. (2001) Managing seasonality in peripheral tourism regions, in BAUM T. and LUNDTORP S. (Eds) Seasonality in Tourism, pp.153-172. Pergamon, Elsevier Science, Oxford, UK.

COSHALL J.T. (2003) The threat of terrorism as an intervention on international travel flows, Journal of Travel Research, 42(1), 4-12.

COSHALL J. T. (2005) Interventions on UK earnings and expenditures overseas, Annals of Tourism Research, 32(3), 592-609.

CUCCIA T. and RIZZO (2011) Tourism seasonality in cultural destinations: empirical evidence from Sicily, Tourism Management, 32(3), 589-595.

DELTAS G. (2003) The small sample bias of the Gini Coefficient: results and implications for empirical research, The Review of Economics and Statistics, 85(1), 226-234. 
DRAKATOS C.G. (1987) Seasonal concentration of tourism in Greece, Annals of Tourism Research, 14(4), 582-586.

EUGENIO-MARTIN, J.L., SINCLAIR, M.T. and YEOMAN I. (2005) Quantifying the effects of tourism crises: an application to Scotland, Journal of Travel and Tourism Marketing, 19(2/3), 21-34.

GETZ D. and NILSSON P.A. (2004) Responses of family businesses to extreme seasonality in demand: the case of Bornholm, Denmark, Tourism Management, 25(1), 17-30.

GINI C. (1912) Variabilità e Mutabilità (Variability and Mutability). Cuppini, Bologna, Italy. Reprinted in PIZETTI E. and SALVEMINI T. (Eds) (1955) Memorie di Metodologica Statistica, Libreria Eredi Virgilio Veschi, Rome, Italy.

HIGHLANDS AND ISLANDS ENTERPRISE (1996) The Economic Impacts of Hillwalking, Montaineering and Associated Activities in the Highlands and Islands of Scotland, Highlands and Islands Enterprise, Inverness.

HINCH T. and JACKSON, E. (2000) Leisure constraints research: its value as a framework for understanding tourism seasonality, Current Issues in Tourism, 3, 87-106.

HOTI S., MCALEER, M. and SHAREFF, R. (2007) Modelling international tourism and country risk spillovers for Cyprus and Malta, Tourism Management, 28(6), 1472-1484.

JANG, S. (2004) Mitigating tourism seasonality: a quantitative approach, Annals of Tourism Research, 31(4), 819-836.

JEFFREY D. and BARDEN R.R.D. (1999) An analysis of the nature, causes and marketing implications of seasonality in the occupancy performance of English hotels, Tourism Economics, 5(1), 69-91.

JEFFREY, D., BARDEN, R.R.D., BUCKLEY, P.J and HUBBARD, N.J. (2002) What makes a successful hotel? Insights on hotel management following 15 years of hotel occupancy in England, The Service Industries Journal, 22(2), 73-88. 
JOHNSTON R., MCKINNEY M. and STARK T. (1996) Regional price level variations and real household incomes in the United Kingdom 1979/80-1993, Regional Studies, 30, $567-587$.

KARAMUSTAFA K. and ULAMA S. (2010) Measuring the seasonality in tourism with the comparison of different methods, EuroMed Journal of Business, 5(2), 191-214.

KASTENHOLZ E. and DE ALMEIDA A.L. (2008) Seasonality in rural tourism - the case of north Portugal, Tourism Review, 63(2), 5-15.

KENNEDY E. and DEEGAN J. (2001) Seasonality in Irish tourism 1973-1995, in BAUM T. and LUNDTORP S. (Eds) Seasonality in Tourism, pp.51-74. Pergamon, Elsevier Science, Oxford, UK.

KING B. (1996) VFR - a future research agenda, in YAMAN H. (Ed) VFR Tourism: Issues and Implications, pp 85-89. Proceedings from the Conference held at Victoria University of Technology, Victoria, Australia.

KOENIG N. and BISCHOFF E. E. (2003) Seasonality of tourism in Wales: a comparative analysis, Tourism Economics, 9(3), 229-254.

KOENIG-LEWIS N. and BISCHOFF E. E. (2005) Seasonality research: the state of the art, International Journal of Tourism Research, 7, 201-219.

KOENIG-LEWIS N. and BISCHOFF E. E. (2010) Developing effective strategies for tackling seasonality in the tourism industry, Tourism and Hospitality Planning and Development, 7(4), 395-413.

KRAKOVER S. (2000) Partitioning seasonal employment in the hospitality industry, Tourism Management, 21(5), 461-471. 
KULENDRAN N. and WONG K.K.F. (2005) Modeling seasonality in tourism forecasting, Journal of Travel Research, 44(2), 163-179.

KUZNETS S. (1932) Seasonal pattern and seasonal amplitude: measurement of their shorttime variations, Journal of the American Statistical Association, 27, 9-20.

LEE G., MORRISON A.M., LHETO, X.Y., WEBB, J. and REID J. (2005) VFR is it really marginal? A financial consideration of French overseas travellers, Journal of Vacation Marketing, 11(4), 340-356.

LUNDTORP S. (2001) Measuring tourism seasonality, in BAUM T. and LUNDTORP S. (Eds) Seasonality in Tourism, pp.23-50. Pergamon, Elsevier Science, Oxford, UK.

MORE N. (2005) Getting down to business, in Capital Review: Quarterly Economic Bulletin from the City of Edinburgh Council Issue 14, pp.6-7. Engage Group, Edinburgh, Scotland.

MORRISON, A.M., VERGINIS, C. and O'LEARY, J.T. (2000) Reaching the unwanted and unreachable: an analysis of the outbound, long haul German and British visiting friends and relatives market, Journal of Tourism and Hospitality Research, 2(3), 214-231.

NADAL J.R., FONT, A.R. and ROSSELLÓ A.S. (2004) The economic determinants of seasonal patterns, Annals of Tourism Research, 31, 697-711.

NESHEIM, T. (2003) Short term hires and the leasing of personnel in Norwegian firms: promoting numerical flexibility and stability, Scandinavian Journal of Management, 19(3), 309-331.

PALANG, H., SOOVALI, H and PRINTSMAN, A. (Eds) (2010) Seasonal Landscapes. Spinger, Dordrecht. 
PORTER M.E. (2003) The economic performance of regions, Regional Studies, 37, 549-578.

SCOTTISH GOVERNMENT (2010) Scottish Government Urban/Rural Classification 20092010, Office of the Chief Statistician, Rural and Environment Research and Analysis Directorate, Scottish Government (available at http://www.scotland.gov.uk /Resource /Doc/933/0103167.pdf).

SEATON A.V. (1998) The marketing of Scotland as a tourist destination, 1985-1996, in MacLELLAN R. and SMITH R. (Eds) Tourism in Scotland, pp. 209-240. International Thomson Business Press, London.

SEATON A. V. and PALMER C. (1997) Understanding VFR tourism behaviour: the first five years of the United Kingdom tourism survey, Tourism Management, 18(6), 345355.

SCOTTISH TOURISM ALLIANCE (2012) Tourism Scotland 2020. Scottish Tourism Alliance: Edinburgh.

SLEE B. (1998) Tourism and rural development in Scotland, in MacLELLAN R. and SMITH R. (Eds) Tourism in Scotland, pp. 70-92. International Thomson Business Press, London.

SPENCER D.M. and HOLECEK D.F. (2007) Basic characteristics of the fall tourism market, Tourism Management, 28(2), 491-504.

VISITSCOTLAND (2007a) Tourism Prospectus: Investing for Growth. VisitScotland: Edinburgh. 
VISITSCOTLAND (2007b) VisitScotland Submission to the Enterprise, Energy and Tourism Committee Tourism Industry Inquiry, December 2007 (available at http://www.visitscotland.org/pdf/Tourism\%20Industry\%20Inquiry.pdf).

VISITSCOTLAND (2013) Tourism Development Plan for Scotland. VisitScotland: Edinburgh.

WALL G. And YAN M. (2003) Disaggregating visitor flows - the example of China, Tourism Analysis, 7(3/4), 191-205.

WANHILL S.R.C. (1980) Tackling seasonality: a technical note, International Journal of Tourism Management, 4, 243-245.

WEN J.J. and TISDELL C.A. (2001) Tourism and China's Development: Policies, Regional Economic Growth and Ecotourism. World Scientific Publishing, Singapore.

YACOUMIS J. (1980) Tackling seasonality: the case of Sri Lanka, International Journal of Tourism Management, 1(2), 84-98. 
Table 1. Results of applying principal components analysis to the regional Gini coefficients for overseas vacation nights

\begin{tabular}{lrcc}
\hline Component & Eigenvalue & \% of variance & Cumulative \% \\
\hline 1 & 3.821 & 29.395 & 29.395 \\
2 & 2.167 & 16.667 & 46.062 \\
3 & 2.157 & 16.590 & 62.651 \\
4 & 1.501 & 11.543 & 74.194 \\
5 & 1.185 & 9.114 & 83.308 \\
\hline
\end{tabular}

Table 2. Rotated component loadings for overseas vacation nights

\begin{tabular}{lcccc}
\hline & \multicolumn{3}{c}{ Component: } \\
\cline { 2 - 4 } IPS region & 1 & 2 & 3 & 5 \\
\hline Argyll & & 0.905 & & \\
Borders & & & & \\
Central & & & 0.863 & \\
Dumfries \& Galloway & 0.795 & & & \\
Fife & 0.782 & & & \\
Glasgow-Clydeside & & & \\
Grampian & & & \\
Highlands & & & \\
Islands & 0.911 & & \\
Lothian & 0.772 & & \\
Strathclyde-Ayr & 0.802 & & \\
Strathclyde-Loch Lomond & & & \\
Tayside \& Perthshire & & & \\
\hline
\end{tabular}


Table 3. Average Gini coefficients and the standard deviations of the amplitude ratios (AR) for Aberdeen, Edinburgh and Glasgow: overseas business nights

\begin{tabular}{llll}
\hline \multirow{2}{*}{ Type of tourism } & \multicolumn{3}{c}{ Mean Gini Coefficients: } \\
\cline { 2 - 4 } & Aberdeen & Edinburgh & Glasgow \\
\hline Business & 0.239 & 0.298 & 0.218 \\
VFR & 0.329 & 0.221 & 0.184 \\
Vacation & 0.450 & 0.416 & 0.393 \\
& & & \\
Standard deviation & 0.614 & 0.530 & 0.878 \\
of AR, business nights & & & \\
\hline
\end{tabular}




\section{Figure Captions:}

Fig. 1. Total numbers of overseas visitor nights spent in the regions of Scotland

Fig. 2. Quarterly percentages of overseas vacation nights spent in each of the regions of Scotland, 1996-2009

Fig. 3. Standard deviation of regional amplitude ratios for overseas vacation nights

Fig. 4. Principal components analysis of regional Gini Coefficients for overseas vacation tourism

Fig. 5. Total numbers of international VFR nights spent in the regions of Scotland

Fig. 6. Mean values of regional Gini coefficients for overseas VFR nights

Fig. 7. Standard deviation of regional amplitude ratios for overseas VFR nights

Fig. 8. Percentages of annual VFR nights spent per quarter in the Glasgow-Clydeside and Lothian regions

Fig. 9. Values of the Gini coefficients for business nights spent in the three dominant urban areas 


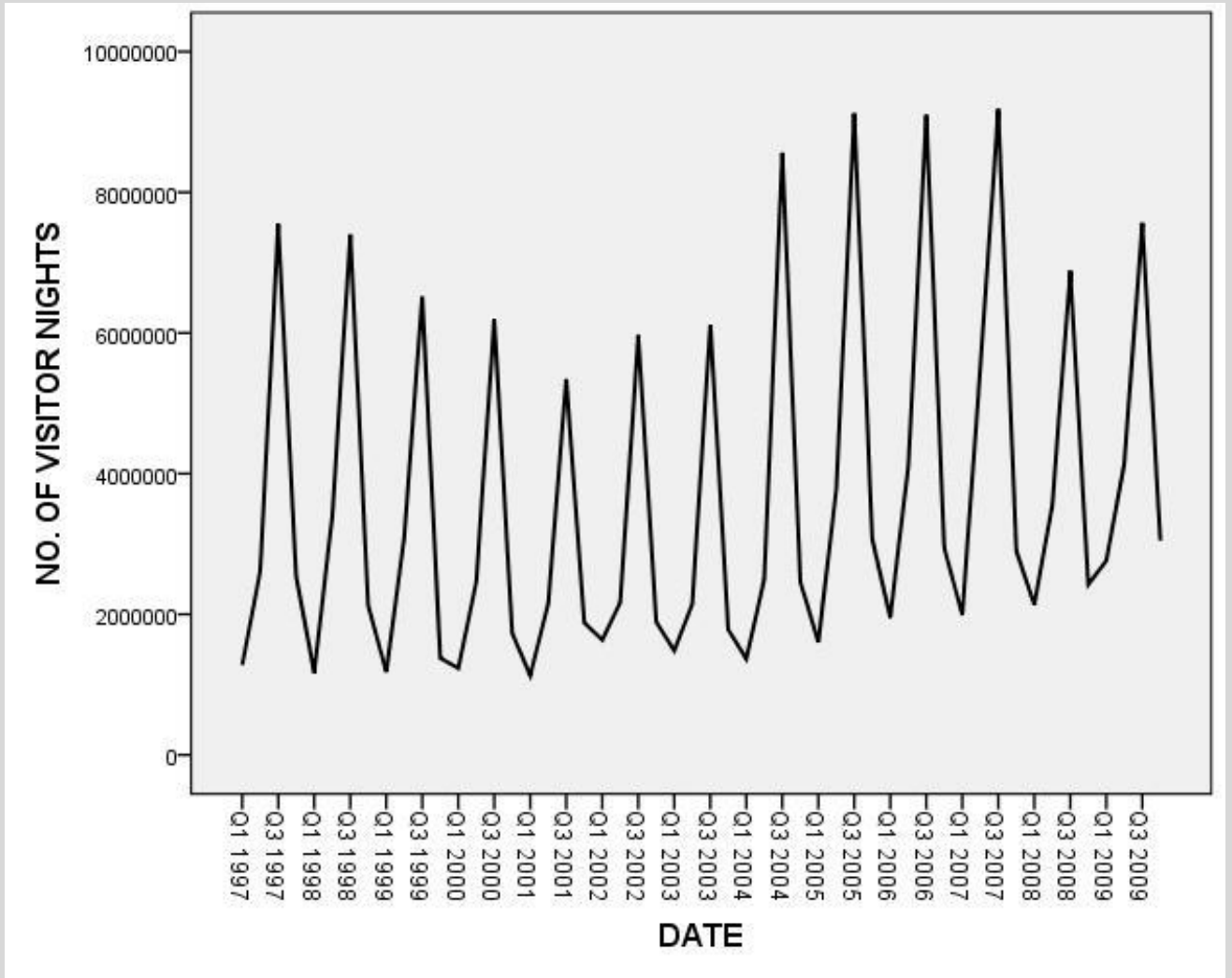




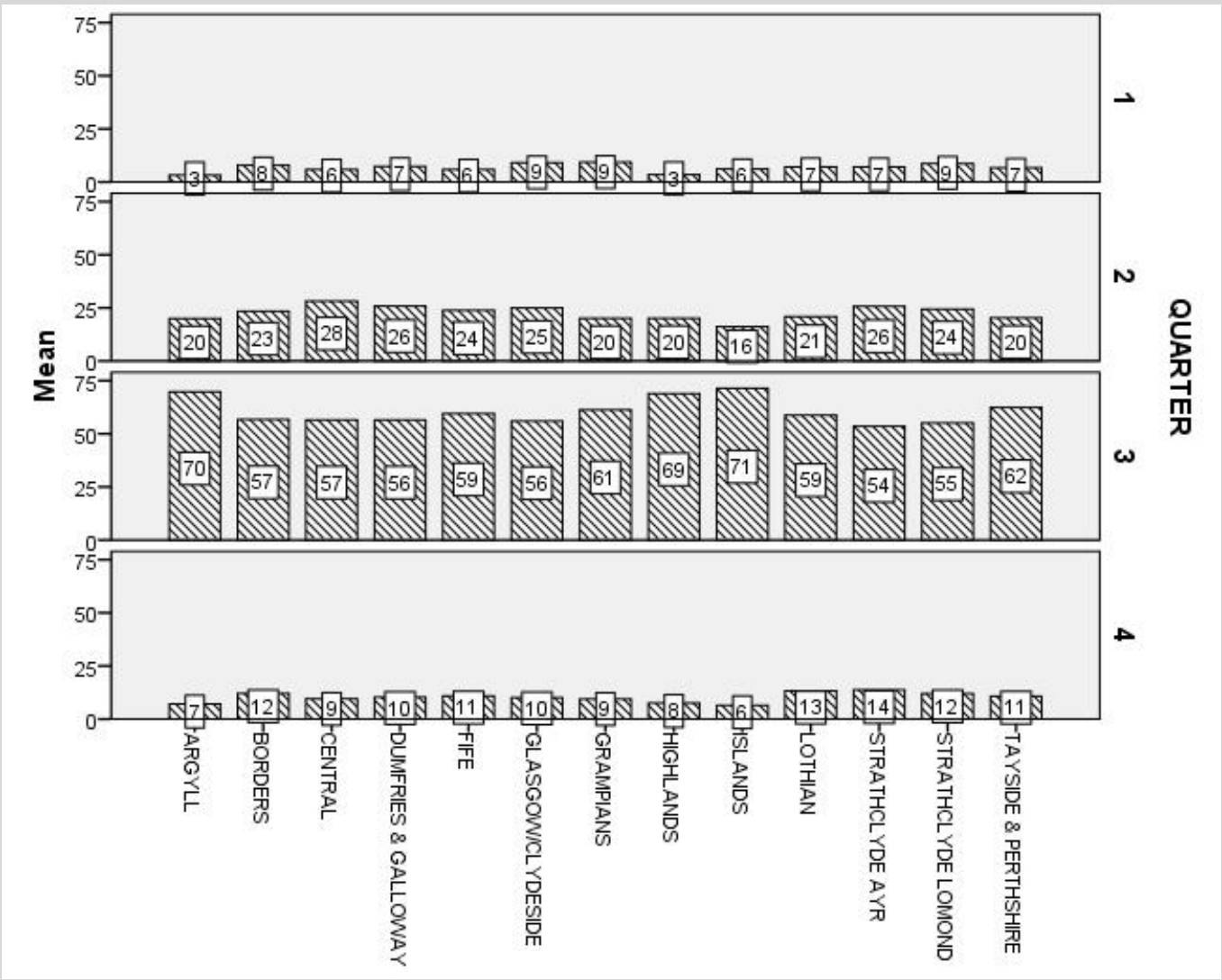




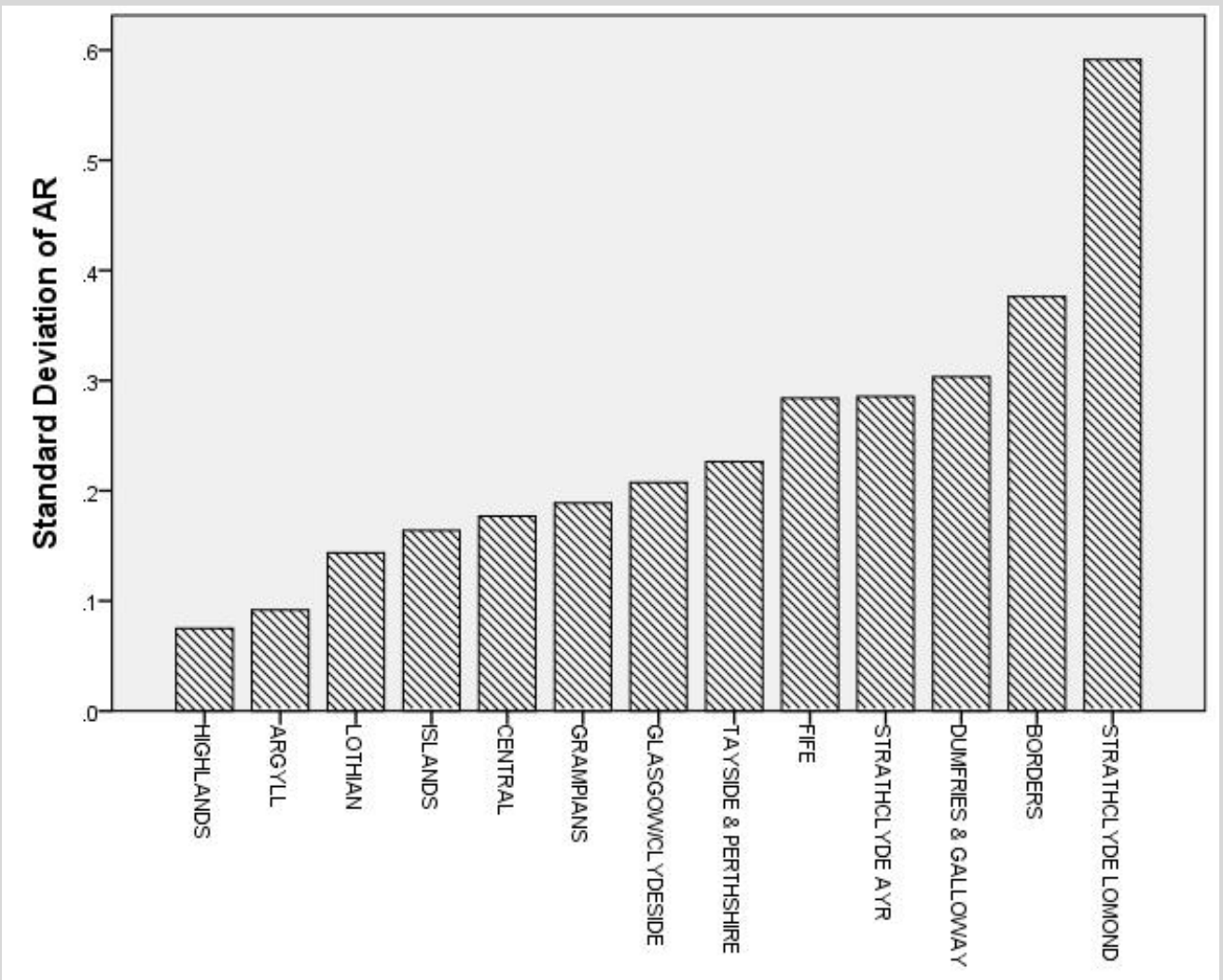




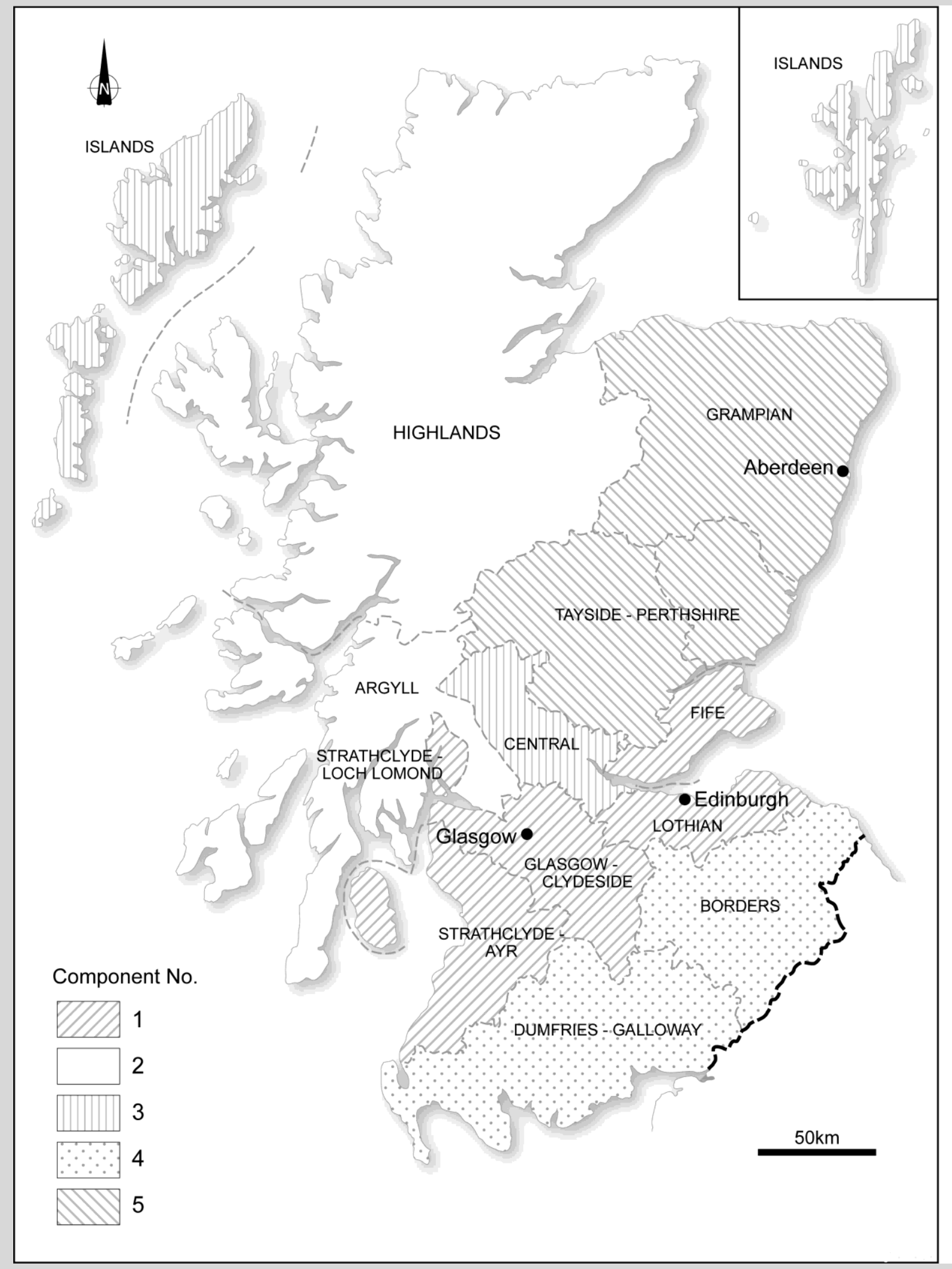




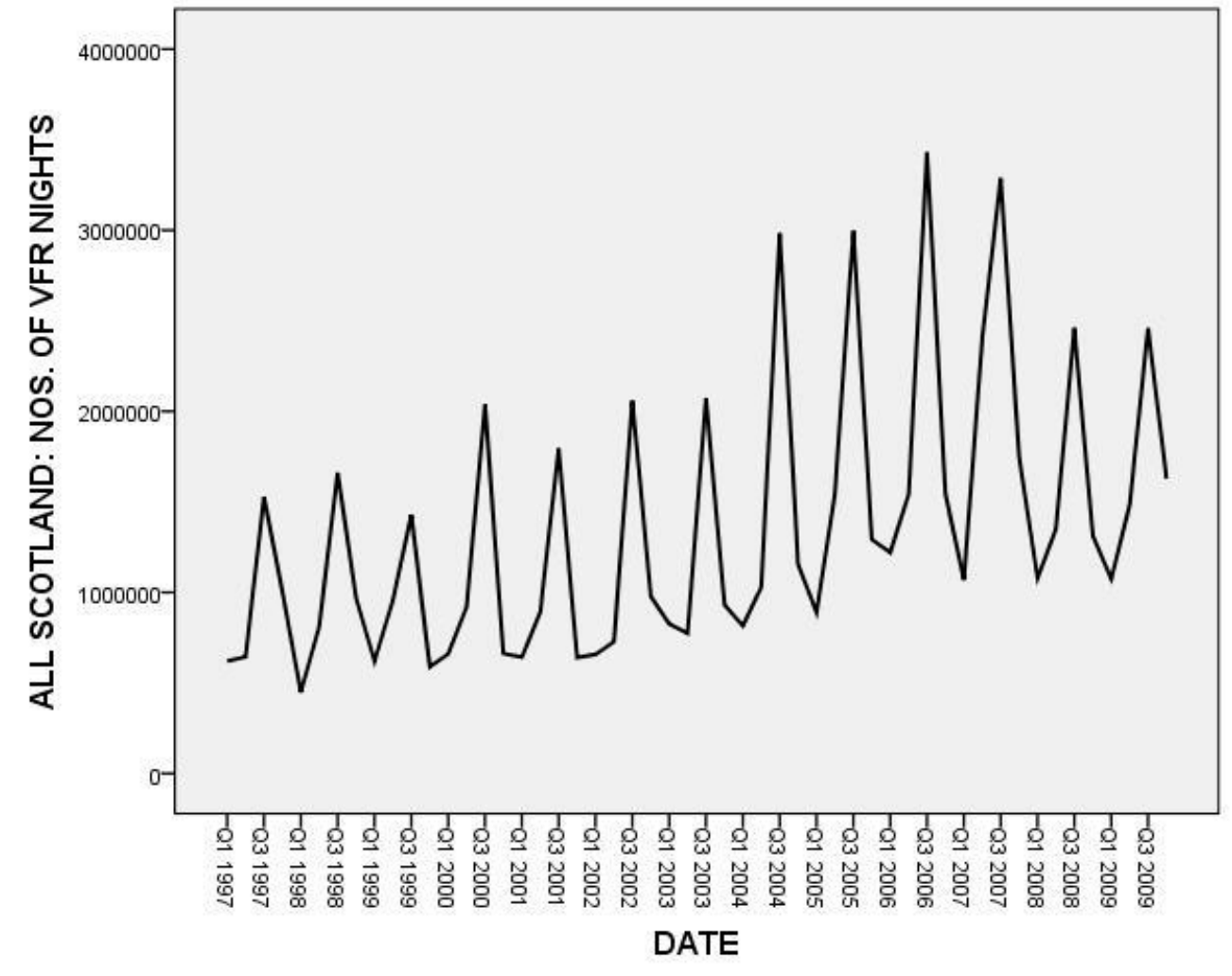




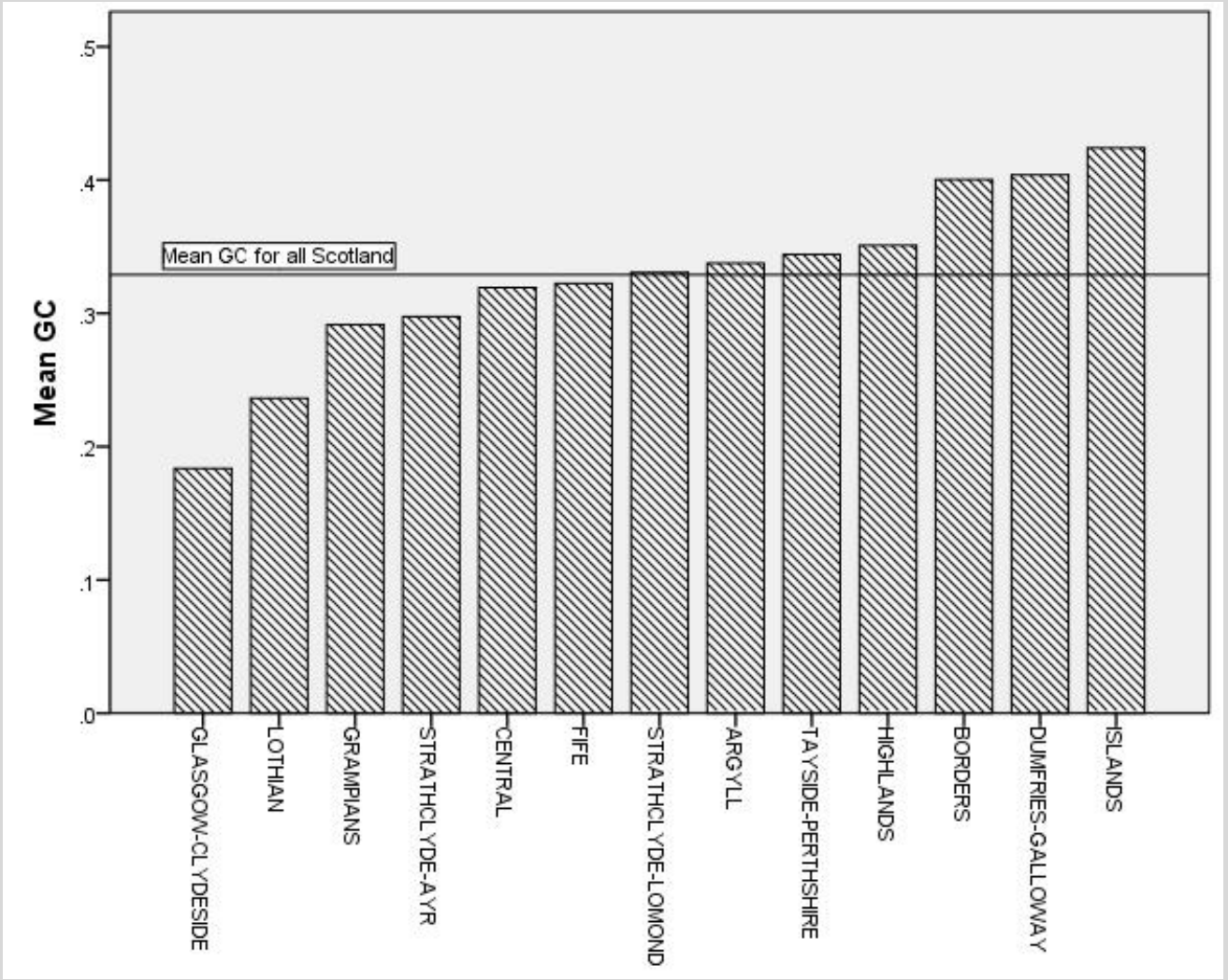




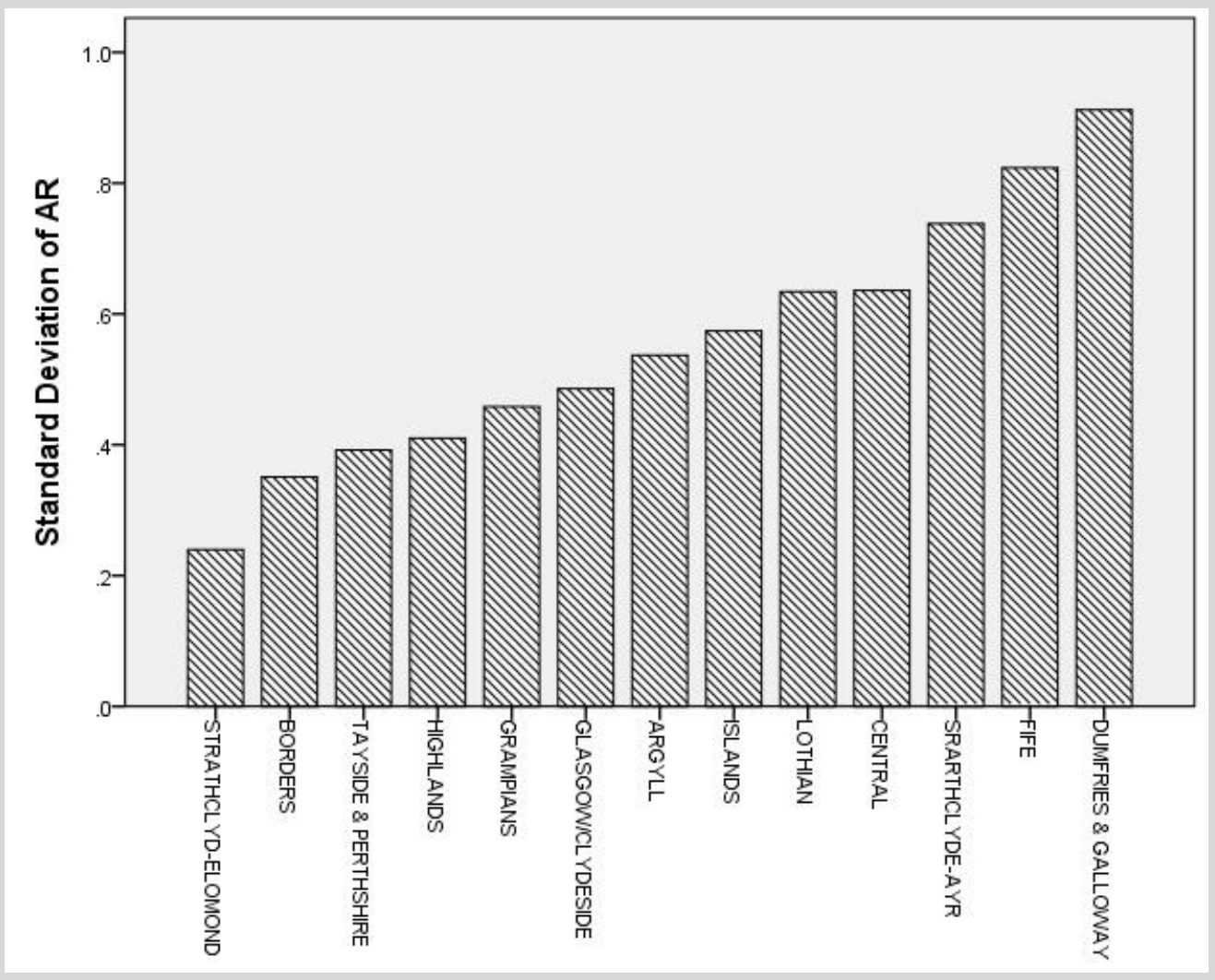




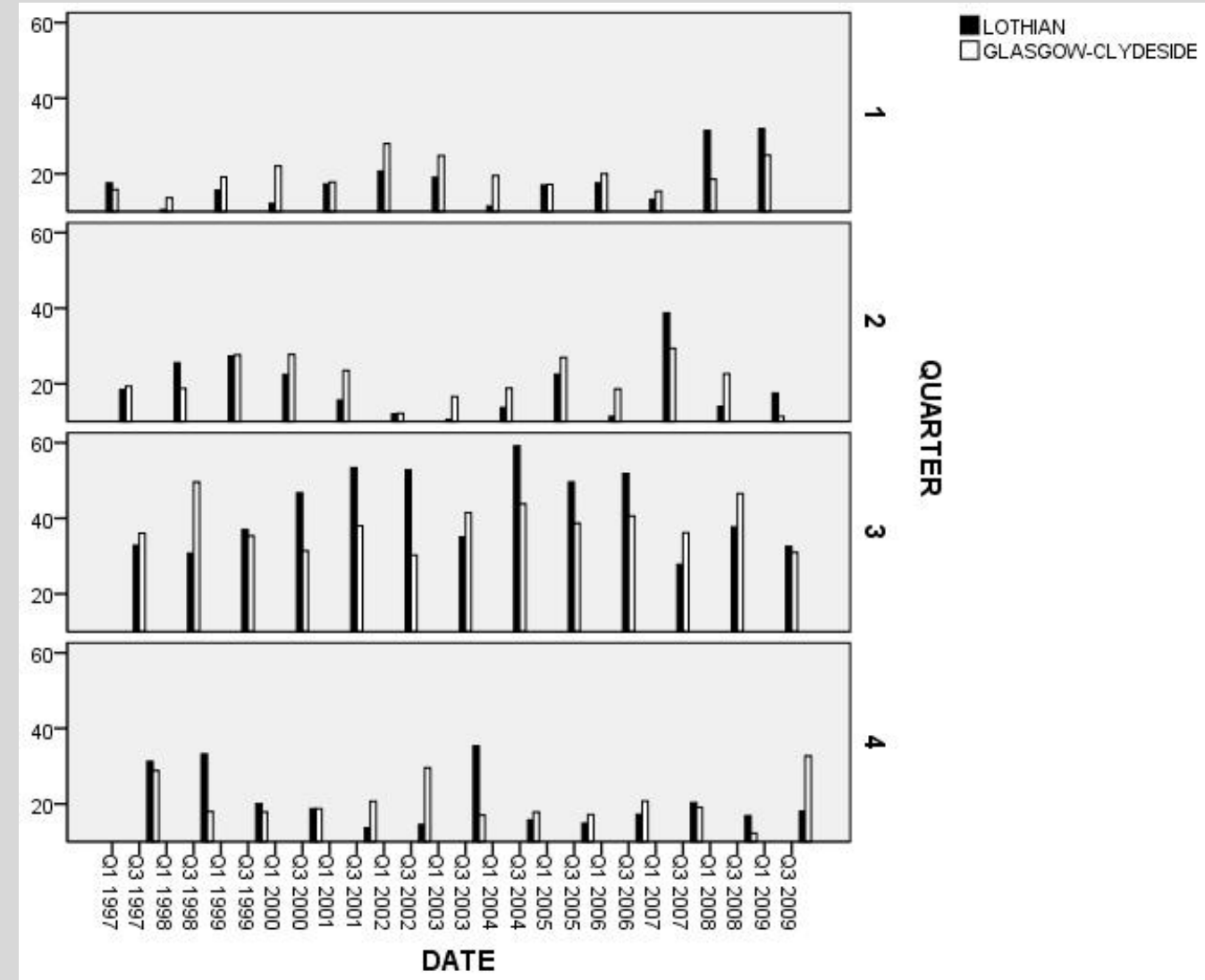




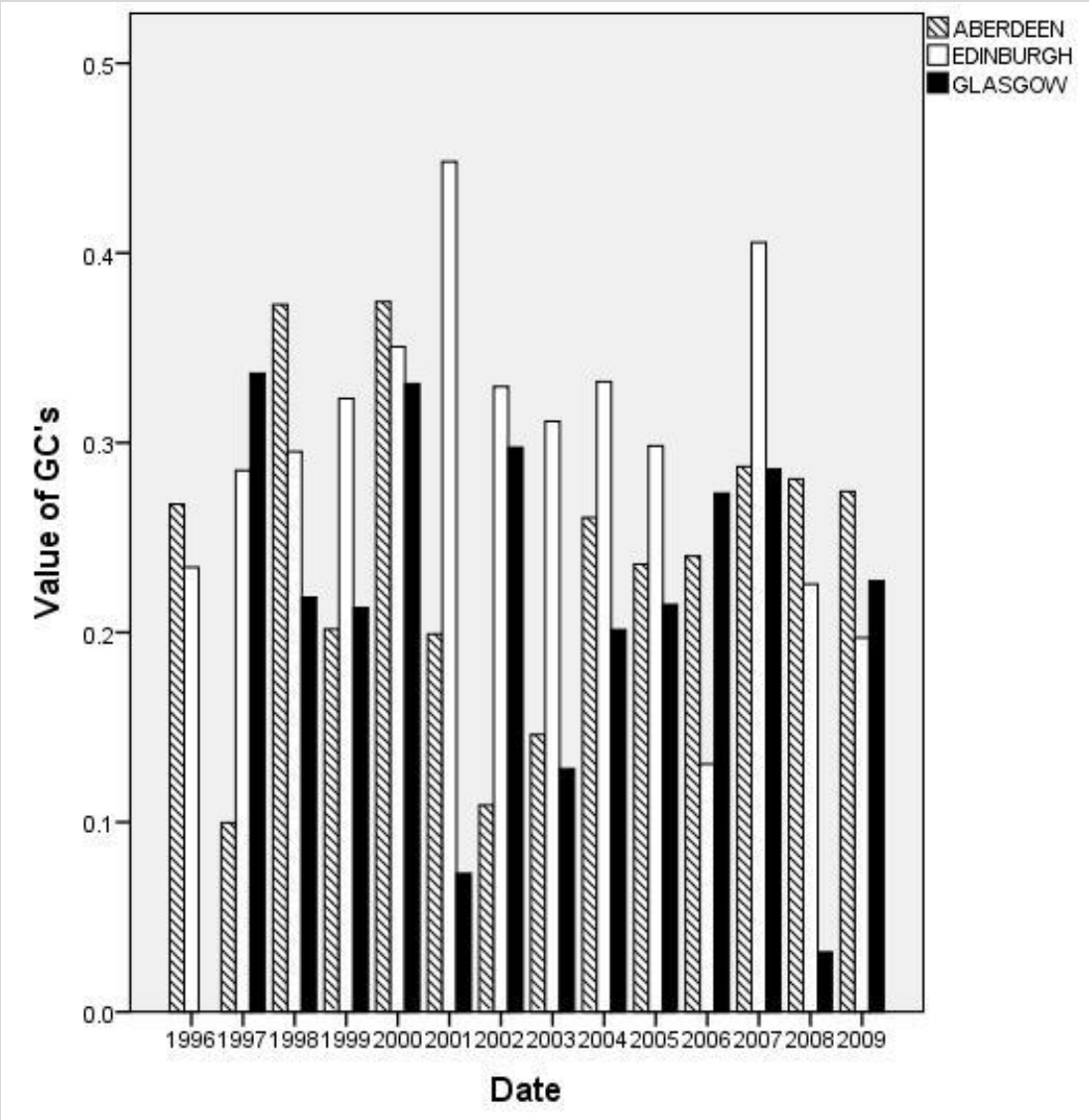


Table 1. Results of applying principal components analysis to the regional Gini coefficients for overseas vacation nights

\begin{tabular}{lrcc}
\hline Component & Eigenvalue & \% of variance & Cumulative \% \\
\hline 1 & 3.821 & 29.395 & 29.395 \\
2 & 2.167 & 16.667 & 46.062 \\
3 & 2.157 & 16.590 & 62.651 \\
4 & 1.501 & 11.543 & 74.194 \\
5 & 1.185 & 9.114 & 83.308 \\
\hline
\end{tabular}


Table 2. Rotated component loadings for overseas vacation nights

\begin{tabular}{|c|c|c|c|c|c|}
\hline \multirow[b]{2}{*}{ IPS region } & \multicolumn{5}{|c|}{ Component: } \\
\hline & 1 & 2 & 3 & 4 & 5 \\
\hline Argyll & & 0.905 & & & \\
\hline Borders & & & & 0.863 & \\
\hline Central & & & 0.868 & & \\
\hline Dumfries \& Galloway & & & & 0.830 & \\
\hline Fife & 0.795 & & & & \\
\hline Glasgow-Clydeside & 0.782 & & & & \\
\hline Grampian & & & & & 0.918 \\
\hline Highlands & & 0.718 & & & \\
\hline Islands & & & 0.944 & & \\
\hline Lothian & 0.611 & & & & \\
\hline Strathclyde-Ayr & 0.772 & & & & \\
\hline Strathclyde-Loch Lomond & 0.802 & & & & \\
\hline Tayside \& Perthshire & & & & & 0.603 \\
\hline
\end{tabular}


Table 3. Average Gini coefficients and the standard deviations of the amplitude ratios (AR) for Aberdeen, Edinburgh and Glasgow: overseas business nights

\begin{tabular}{llll}
\hline \multirow{2}{*}{ Type of tourism } & \multicolumn{3}{c}{ Mean Gini Coefficients: } \\
\cline { 2 - 4 } & Aberdeen & Edinburgh & Glasgow \\
\hline Business & 0.239 & 0.298 & 0.218 \\
VFR & 0.329 & 0.221 & 0.184 \\
Vacation & 0.450 & 0.416 & 0.393 \\
& & & \\
Standard deviation & 0.614 & 0.530 & 0.878 \\
of AR, business nights & & & \\
\hline
\end{tabular}




\title{
Methodological Footnotes
}

\begin{abstract}
'Seasonality is often measured using visitors arrival data, accommodation occupancy levels, traffic levels, demand for public transport, tourists' expenditures, employment in the sector or admission numbers to tourist
\end{abstract} attractions.

ii This manifests itself as high levels of accommodation occupancy in July and August, with large numbers of unfilled beds in the shoulder season (March-June, September-October) and off-peak seasons (VISITSCOTLAND, 2007a).

iii Up to 2000 a structural decline occurred 1996-2000 which led to a Parliamentary Inquiry on the performance of the former Scottish Tourist Board and its leadership in tourism; post-2000 public sector intervention led to enhanced spending on tourism promotion with the formation of VisitScotland in 2002. Yet there are also debates within the wider tourism marketing profession that spend on destination marketing does not directly lead to increases in visitation and that is a necessity to remain competitive (i.e. a hygiene factor), as other destinations aggressively promote their wares. Irrespective of the perspective one adopts, it is still pertinent to assess whether a recognition of marketing spend to attract visitors has affected the shape and form of seasonality year on year. Therefore, the paper adopts a long timeframe so as to capture a meaningful time series (albeit being punctuated by global events that shaped international tourism such as $9 / 11$ and Foot and Mouth Disease that impacted arrivals in 2001 and 2002).

iv At the time of data extraction from the raw IPS files, the UK Office for National Statistics had discovered errors in the 2010 files and these were removed from the public domain. Quarterly data are the manner in which the survey data are collected and so whilst many other comparable studies (e.g. KOENIG and BISCHOFF, 2003) use monthly data, it is important to acknowledge this limitation in the dataset. In addition, a further methodological issue to recognise is that using quarterly data may slightly bias the patterns of seasonality in quarters 1 and 2 since for 4 of the 14 years examined, the Easter holidays occurred in late March. The IPS collects information on behalf of the UK Office for National Statistics about overseas passengers entering and leaving the UK. The survey results are used by a range of bodies including VisitBritain (the national tourism agency) and the tourism organisations for London, England, Wales and Scotland (VisitScotland) for the purposes of assessing the impact of tourists' expenditure and taxation on the UK economy, estimating migration rates and monitoring changes in international tourism over time. For example, in 2009 the IPS employed a multi-stage random sample of over 311000 people (representing about $0.2 \%$ of all travellers to and from the UK), who were interviewed at all the major airports, sea routes, Eurostar terminals and on Eurotunnel trains. In order to extract information concerning international visitors to the various regions of Scotland, it was necessary to access the raw IPS data files which are available for download in SPSS format from the UK Data Archive.

${ }^{v}$ This paper utilises the Gini Coefficient as a technique, building on the studies in Baum and Lundtorp (2001) and Koening and Bischoff (2003) to measure the degree of stability in regional vitiation. The amplitude ratio was selected as a measure to assess the seasonal patterns over time (year on year) to assess whether the concentration of visits was increasing or decreasing through time. Additional measures to assess the spatial element were also employed including a Principal Components Analysis.

${ }^{\text {vi }}$ Counts for 1996 are omitted from Fig. 1, since codes for vacation nights to the Strathclyde-Loch Lomond, Glasgow-Clydeside and Tayside-Perthshire regions are missing from the IPS files for that year.

vii This is the commonly cited element in the identification of a core-periphery model of spatially contingent seasonality in Scotland.

viii It might be noted that plots of Gini Coefficients for overseas nights by region suggest that variations in the strength of seasonal patterns may be cyclical in nature. This point merits further research. 
${ }^{\text {ix }}$ Principal Components Analysis was used as a technique to group the geographical (i.e. regional) elements of the GC to test for the degree of spatial clustering of regions (i.e. reductionism). This facilitates the reduction of the complexity of the GCs at a regional level to be grouped into a series of categories for further analysis in terms of what is leading to regional similarities in GCs. It is the starting point for a greater focus on the spatial analysis of seasonality.

${ }^{x}$ The Scottish Government's classification of urban ( $>3000$ people) and rural $(<3000$ people) zones categorises this component as being entirely made up of 'accessible urban and rural areas' (SCOTTISH GOVERNMENT, 2010). "Accessible" is defined as being within a thirty minute drive time of a settlement of 10000 or more people.

${ }^{x i}$ Within a drive time of between 30 and 60 minutes of a settlement of 10000 or more.

xii With a drive time in excess of 60 minutes to a settlement of 10000 or more.

xiii It might be noted that there are a few times when quarter 3 is not the peak period for VFR nights and that quarter 2 is very occasionally the off-peak period.

${ }^{\text {xiv }}$ However, in terms of economic impact, it is domestic business tourism which has a proportionately higher economic impact per visitor than overseas visitors (i.e. business tourism is $16 \%$ of domestic visits in 2009 but $22 \%$ of spending).

${ }^{\mathrm{xv}}$ Between 1994 and 2000, the GC for domestic demand for business tourism to Scotland averaged 0.166 (KOENIG and BISCHOFF, 2003) suggesting that domestic business tourism exhibits marginally less seasonal inequality than does its international equivalent. 